\title{
BMJ Open Quality Using a report card to increase HIV screening in a large primary care group practice
}

Mitchell N Luu (D) , ${ }^{1}$ Paul Y Wada, ${ }^{2}$ Tory Levine-Hall, ${ }^{3}$ Leo Hurley, ${ }^{3}$ Nirmala Ramalingam, ${ }^{2} \mathrm{H}$ Nicole Tran, ${ }^{2}$ Sally B Slome ${ }^{4}$

To cite: Luu MN, Wada PY, Levine-Hall T, et al. Using a report card to increase HIV screening in a large primary care group practice. BMJ Open Quality 2021;10:e000988. doi:10.1136/ bmjoq-2020-000988

Received 6 April 2020 Revised 8 December 2020 Accepted 29 December 2020
Check for updates

(C) Author(s) (or their employer(s)) 2021. Re-use permitted under CC BY-NC. No commercial re-use. See rights and permissions. Published by BMJ.

${ }^{1}$ Adult and Family Medicine, Kaiser Permanente 0akland Medical Center, Oakland, California, USA

${ }^{2}$ Graduate Medical Education, Kaiser Permanente Oakland Medical Center, Oakland, California, USA

${ }^{3}$ Division of Research, Kaiser Permanente Northern California, Oakland, California, USA

${ }^{4}$ Infectious Diseases, Kaiser Permanente Oakland Medical Center, Oakland, California, USA

Correspondence to

Dr Mitchell N Luu;

mitchell.n.luu@kp.org

\section{ABSTRACT}

Background Despite increased efforts to promote HIV screening, a large proportion of the US population have never been tested for HIV.

Objective To determine whether provider education and personalised HIV screening report cards can increase HIV screening rates within a large integrated healthcare system.

Design This quality improvement study provided a cohort of primary care physicians (PCPS) a brief educational intervention and personalised HIV screening report cards with quarterly performance data.

Participants Participants included a volunteer cohort of 20 PCPs in the department of adult and family medicine.

Main measures Per cent of empaneled patients screened for HIV by cohort PCPs compared with PCPs at the Kaiser Permanente Oakland Medical Center (KPOAK) and the non-Oakland Medical Centers in Northern California region (Kaiser Permanente Northern California (KPNC)).

Key results Of the 20 participating PCPs, 13 were female and 7 were male. Thirteen were internal medicine and seven family medicine physicians. The average age was 40 years and average practice experience was 9 years after residency. During the 12-month intervention, the estimated increase in HIV screening in the cohort PCP group was $2.6 \%$ as compared with $1.9 \%$ for KPOAK and $1.8 \%$ for KPNC.

Conclusions These findings suggest that performancerelated report cards are associated with modestly increased rates of HIV screening by PCPS.

\section{INTRODUCTION}

HIV continues to infect patients in the USA. ${ }^{1}$ The Centers for Disease Control and Prevention (CDC) first adopted universal screening guidelines in 2006 to curb the spread of HIV and the United States Preventive Services Task Force (USPSTF) recently updated their guidelines in 2019 with a grade A recommendation on universal HIV screening in adolescents, adults and pregnant women. ${ }^{23}$ Despite these recommendations, there are an estimated 162500 people in the USA unknowingly living with the disease. ${ }^{1}$

Current screening data show a significant lag in implementation of universal HIV screening. ${ }^{4}$ About $14.2 \%$ of the US population living with HIV remains undiagnosed and only $39.6 \%$ of non-institutionalised adults have ever been screened. ${ }^{15}$ Only a quarter of untested high-risk patients describe being offered HIV screening at routine health visits within the past year, and some patients may not disclose high-risk behaviours to their primary care provider. ${ }^{6}$ These numbers have remained relatively stable for the past decade with only small incremental improvements, showing that more can be done to advance the implementation of HIV screening guidelines. 57

Studies have shown that physician lack of knowledge and practices may be driving low screening rates. In one study, only half of internal medicine residents were aware of the screening guidelines. ${ }^{8}$ In an emergency department setting, many providers were supportive of a testing programme, but fewer were willing to routinely offer HIV screening. ${ }^{9}$ Survey data documented barriers including poor overall awareness, time constraints, inadequate linkage-to-care and legal obligations to document consent. ${ }^{9} 10$ Another study targeted physician preferences for HIV screening programmes, which highlighted the need for updates on education on HIV screening guidelines, local leadership backing and regular prompting to promote screening. ${ }^{11}$

Audit and feedback can address several possible barriers to universal HIV screening, advancing both awareness and physician perceptions while also providing a regular stimulus for screening. ${ }^{12-14}$ Such methods offer external, objective assessments with evidence to support improved compliance with desired practices. ${ }^{15}$ Our study aims to direct audit and feedback towards increasing provider guideline awareness and to improve HIV screening rates. We hypothesised that audit and feedback in the form of quality performance report cards would increase 
HIV screening rates in a large group primary care practice.

\section{METHODS}

\section{Setting and study population}

We conducted the study from March 2018 through March 2019 at the Kaiser Permanente Oakland Medical Center (KPOAK). Kaiser Permanente (KP) is an integrated healthcare delivery system that provides comprehensive care to a diverse population in Northern California. This quality improvement study was designed to supplement standard physician practices. At the time of recruitment, there were 125 primary care physicians (PCPs) in the Department of Adult and Family Medicine at the KP Oakland Medical Center. PCPs were recruited through a written communication to the department. PCPs gave verbal consent and voluntarily participated.

\section{Survey data and educational intervention}

Based on a literature review by Burke $e t$ al, we constructed a preintervention survey to assess knowledge of HIV screening guidelines and perceived barriers to HIV screening. ${ }^{16}$ In March 2018, cohort PCPs were given the preintervention survey and SurveyMonkey (San Mateo, California) was used to collect deidentified survey data. After survey completion, cohort PCPs were given a brief, one-page educational handout with USPSTF HIV screening recommendations and provided information on screening consent, disclosure protocols and referral information if tests returned positive. Cohort PCPs were encouraged to screen all patients age 13-64 at least once per CDC and USPSTF guidelines and offer an HIV test unless the patient declines (opts-out). PCPs were also instructed on how to use templates integrated in the electronic medical record (Epic, Verona, Wisconsin, USA) to assist with documentation after obtaining verbal consent for HIV testing.

\section{Data collection}

The data set was comprised of eligible KP members aged 13-64 who remained on a single PCP panel for at least 6 months prior to the reference date of 31 December 2017. Members were excluded from the data set if they changed PCPs, changed membership status with KP or aged out of the screening guidelines at 65 years. No additional patients were added to the data set after 31 December 2017. HIV testing data were collected by PCP panel and divided into three different PCP groups in order to compare the effects of the HIV screening report card intervention. First, data were collected from the PCPs involved in the intervention (cohort PCP). Second, data from the remaining PCPs in the Department of Adult and Family Medicine at KPOAK were collected as a reference to compare the intervention group to their peers. Third, data from the non-Oakland PCPs were collected as a non-intervention reference. Deidentified, aggregated HIV testing data were extracted from the KPNC regional laboratory data system.

\section{HIV screening report cards}

At the start of the study, PCP-specific baseline report cards were given individually to each PCP. The report card showed the per cent of eligible panel members who received HIV testing of their respective patient panel. The report card also ranked PCPs in comparison to their peers in the cohort. Over 12 months, PCPs received a quarterly report card on HIV screening percentages compared with other PCPs in the cohort.

\section{Statistical analysis}

We used Poisson regression to model screening rates per 100 people with terms for group (cohort PCP, KPOAK and $\mathrm{KPNC}$ ), interval (baseline and intervals 1-4) and interaction terms for group/interval. We then measured linear trends in the screening rate over time by group based on $\chi^{2}$ tests. We also determined whether the linear trends were different across groups based on the interaction term $\mathrm{p}$ values.

\section{RESULTS}

Twenty PCPs (16\% of Oakland-based PCPs) consented to participate in the HIV screening report card intervention. Seven were male and thirteen were female, with thirteen practicing internal medicine and seven practicing family medicine (table 1 ). The average PCP age was 40 years with 9 years of practice after residency. PCP locations were in three separate buildings of the Kaiser Permanente Oakland medical campus. One PCP withdrew from the study after interval 2 and another PCP withdrew from the study after interval 3. Both PCPs withdrew due to transfers in medical practices. Data from both PCPs were included until the date of withdrawal from the study.

Survey results from 19 PCPs (response rate: 95\%) showed that $84 \%$ felt familiar with current CDC and USPSTF guidelines for HIV screening, with $58 \%$ screening according to CDC and USPSTF guidelines (table 1). Three PCPs felt that they were screening fewer than five patients per month. The most frequently cited barriers to screening were competing priorities $(58 \%)$, insufficient time (42\%) and lack of perceived risk (37\%). Other barriers cited included a burdensome consent process $(21 \%)$, cultural barriers $(21 \%)$ and fear or concern of offending the patient $(21 \%)$. Only one $(5 \%)$ PCP acknowledged a lack of knowledge or training as a barrier to screening.

At baseline (1 March 2018), 19008 members met eligibility and were included in the cohort PCP group. Of those members, $50.5 \%$ had received HIV testing at least once (table 2). This contrasted with $38.1 \%$ of 163968 eligible members in the KPOAK group and $29.2 \%$ of 2912259 eligible members in the KPNC group.

The HIV screening report card intervention started in March 2018 and cohort PCPs were given quarterly report cards with their screening rates compared with other PCPs in the cohort (figure 1). For the first interval (1 March 2018 to 30 June 2018), there was an increase in screening 
Table 1 Provider demographics and knowledge of HIV screening guidelines and perceived barriers

\begin{tabular}{ll}
\hline Provider demographics & $\begin{array}{l}\text { No. } \\
(\mathbf{n}=\mathbf{2 0})\end{array}$ \\
\hline Male & 7 \\
\hline Female & 13 \\
\hline Internal medicine & 7 \\
\hline Family medicine & 13 \\
\hline Average age (years) & 40.4 \\
\hline Average years of practice & 9 \\
\hline Survey data & $\begin{array}{l}\text { No. (\%) } \\
(\mathbf{n}=19)\end{array}$
\end{tabular}

I am familiar with the CDC and USPSTF guidelines for HIV screening

\begin{tabular}{|c|c|}
\hline Strongly agree and agree & $16(84 \%)$ \\
\hline $\begin{array}{l}\text { Neither agree nor disagree, disagree, } \\
\text { and strongly disagree }\end{array}$ & $3(16 \%)$ \\
\hline \multicolumn{2}{|c|}{ I feel comfortable screening my patients for HIV } \\
\hline Strongly agree and agree & $19(100 \%)$ \\
\hline $\begin{array}{l}\text { Neither agree nor disagree, disagree, } \\
\text { and strongly disagree }\end{array}$ & $0(0 \%)$ \\
\hline \multicolumn{2}{|c|}{ Which best describes your HIV screening practice? } \\
\hline $\begin{array}{l}\text { I screen all patients, with more } \\
\text { frequent screening based on risk } \\
\text { factors }\end{array}$ & $11(58 \%)$ \\
\hline $\begin{array}{l}\text { I screen my patients only if there are } \\
\text { risk factors }\end{array}$ & $5(26 \%)$ \\
\hline $\begin{array}{l}\text { I screen my patients once, regardless } \\
\text { of risk factors }\end{array}$ & $2(11 \%)$ \\
\hline I do none of the above statements & $1(5 \%)$ \\
\hline \multicolumn{2}{|l|}{$\begin{array}{l}\text { On average, I screen __ patients for HIV } \\
\text { in a given month }\end{array}$} \\
\hline Fewer than 5 & $3(16 \%)$ \\
\hline $5-10$ & $7(37 \%)$ \\
\hline $11-20$ & $5(26 \%)$ \\
\hline More than 20 & $4(21 \%)$ \\
\hline
\end{tabular}

What are the barriers for you in screening patients for HIV? (select all that apply)

\begin{tabular}{|ll}
\hline Competing priorities & $11(58 \%)$ \\
\hline Insufficient time & $8(42 \%)$ \\
\hline Lack of perceived risk for patient & $7(37 \%)$ \\
\hline Cultural barriers & $4(21 \%)$ \\
\hline Fear/concern of offending patient & $4(21 \%)$ \\
\hline Burdensome consent process & $4(21 \%)$ \\
\hline Lack of provider knowledge/training & $1(5 \%)$ \\
\hline $\begin{array}{l}\text { Discomfort discussing sexual history } \\
\text { and identifying high-risk individuals }\end{array}$ & $0(0 \%)$ \\
\hline $\begin{array}{l}\text { Uncertain follow-up and disclosures of } 0(0 \%) \\
\text { test results (specifically if positive) }\end{array}$ \\
\hline
\end{tabular}

CDC, Centers for Disease Control and Prevention; USPSTF, United States Preventive Services Task Force. of $1.5 \%$ for the cohort group, $0.9 \%$ for the KPOAK group and $0.6 \%$ for the KPNC group. The second, third and fourth intervals (1 July 2018 to 30 September 2018, 1 October 2018 to 31 December 2018 and 1 January 2019 to 31 March 2019), respectively, all showed similar increases in HIV screening.

We used Poisson models to estimate changes in HIV screening in each group (cohort PCP, KPOAK and KPNC) over time. Over the 12-month period, the cohort PCP group had a $2.6 \%$ estimated increase in HIV screening per 100 patients as compared with $1.9 \%$ for KPOAK and $1.8 \%$ for KPNC (table 3 ). Each group experienced a statistically significant (all $\mathrm{p}$ values $<0.0001$ ) estimated change in HIV screened per cent over the 12-month intervention. The difference in the trend experienced with the cohort PCP group compared with KPNC was significant ( $p$ value $=0.02$ ). The cohort PCP group was not significant when compared with Oakland ( $\mathrm{p}$ value $=0.07$ ). We also found the difference in trend experienced for KPOAK was not significant when compared with the KPNC ( $p$ value $=0.33$ ).

\section{DISCUSSION}

HIV screening, prevention and treatment are national priorities with vast implications on morbidity and mortality. Recently, the USPSTF reaffirmed the importance of universal HIV screening in adolescents and adults in their recent guidelines. ${ }^{3}$ Our quality improvement study shows that an intervention consisting of brief review of HIV screening guidelines and quarterly performancerelated report cards is associated with an increased rate of HIV screening and can help motivate PCPs to screen their patient population for HIV.

Quality improvement projects performed in various primary care and specialist settings have increased HIV screening rates but the effects have been either small and not population based. ${ }^{17-19}$ Using concepts of audit and feedback to improve practice outcomes, we identified a need for quality improvement and an attainable goal to increase HIV screening rates within our KP healthcare system. ${ }^{20}{ }^{21}$ Using successive rounds of real-time audit and feedback in the form of a HIV screening report card, cohort PCPs were given a summary of their clinical performance and were compared with their peers. As a result, we saw estimated overall increase in $2.6 \%$ during the 12-month intervention. These results are significant since PCPs within KP have large panel sizes (often greater than 1000 members per PCP), which can make percentage changes appear small. In addition, the study offered a limited time window since not all members will be seen by the PCP to be offered HIV screening during the 12-month intervention.

At baseline, the cohort PCP group had a higher per cent of their panel screened for HIV compared with KPOAK and KPNC. Several factors could contribute to these differences. Composition of patient panels may have differed between the intervention group and the KPOAK 
Table 2 Counts and percentages of eligible members ever screened for HIV over 12-month intervention

\begin{tabular}{|c|c|c|c|c|c|}
\hline & $\begin{array}{l}\text { Baseline data (1 } \\
\text { January2018 to } 31 \\
\text { March 2018) }\end{array}$ & $\begin{array}{l}\text { Interval } 1 \text { (1 April } 2018 \\
\text { to } 30 \text { June 2018) }\end{array}$ & $\begin{array}{l}\text { Interval } 2 \text { ( } 1 \text { July } 2018 \\
\text { to } 30 \text { September } 2018 \text { ) }\end{array}$ & $\begin{array}{l}\text { Interval } 3 \text { (1 October } \\
2018 \text { to } 31 \text { December } \\
\text { 2018) }\end{array}$ & $\begin{array}{l}\text { Interval } 4 \text { (1 January } \\
2019 \text { to } 31 \text { March } \\
\text { 2019) }\end{array}$ \\
\hline Cohort PCP & $\begin{array}{l}9606 / 19008 \\
(50.5 \%)\end{array}$ & $\begin{array}{l}9415 / 18092 \\
(52.0 \%)\end{array}$ & $\begin{array}{l}9112 / 17104 \\
(53.3 \%)\end{array}$ & $\begin{array}{l}8434 / 15346 \\
(54.4 \%)\end{array}$ & $\begin{array}{l}7845 / 14029 \\
(56.0 \%)\end{array}$ \\
\hline KPOAK & $\begin{array}{l}62471 / 163968 \\
(38.1 \%)\end{array}$ & $\begin{array}{l}62274 / 159730 \\
(39.0 \%)\end{array}$ & $\begin{array}{l}61463 / 154829 \\
(39.7 \%)\end{array}$ & $\begin{array}{l}61475 / 151947 \\
(40.5 \%)\end{array}$ & $\begin{array}{l}60572 / 147565 \\
(41.0 \%)\end{array}$ \\
\hline KPNC & & $\begin{array}{l}\% \text { change baseline to } \\
\text { interval } 1\end{array}$ & $\begin{array}{l}\% \text { change interval } 1 \text { to } \\
\text { interval } 2\end{array}$ & $\begin{array}{l}\% \text { change interval } 2 \text { to } \\
\text { interval } 3\end{array}$ & $\begin{array}{l}\% \text { change interval } 3 \\
\text { to interval } 4\end{array}$ \\
\hline Cohort PCP & & $1.5 \%$ & $1.2 \%$ & $1.1 \%$ & $1.6 \%$ \\
\hline KPOAK & & $0.9 \%$ & $0.7 \%$ & $0.8 \%$ & $0.6 \%$ \\
\hline KPNC & & $0.6 \%$ & $0.5 \%$ & $0.5 \%$ & $0.5 \%$ \\
\hline
\end{tabular}

KPNC, Kaiser Permanente Northern California; KPOAK, Kaiser Permanente Oakland Medical Center; PCP, primary care physician.

or KPNC groups. Differences in panel composition with a higher percentage of women, youth, certain racial groups and country of origin may influence baseline data and screening rates. ${ }^{22-25}$ Another difference is that the cohort PCP group had relatively high HIV screening awareness compared with other groups. ${ }^{86}$ Prior studies show that PCP failure to offer testing is major contributor to low screening rates. ${ }^{162627}$ The PCPs in our intervention group are relatively young, actively volunteered to be in the intervention, and were familiar with the HIV screening guidelines and perhaps more likely to offer HIV screening.

There were a few limitations to our study. Collectively, the cohort PCP group had a significant increase in HIV screening compared with the regional comparison. However, the increase in HIV screening was not universal for all participants of the intervention group. The per cent change in HIV screening ranged from $0.3 \%$ to $12.3 \%$. Fifteen of the PCPs had over 3\% increase where two had less than $1 \%$ increase. The intervention influenced most of the cohort PCPs but had little effect on a few. No additional interventions or surveys were performed to determine the difference in motivation or participation by cohort PCPs.

The study was also limited since the intervention occurred at a single location in a smaller cohort of PCPs that were not randomly selected. Since the cohort PCPs practices are colocated with other Oakland PCPs, the knowledge of the HIV screening report card intervention could have peripherally influenced other PCPs to increase their HIV screening practices. Cohort PCPs will often cross cover and see patients from non-cohort PCPs, which could influence the data. Eligible members in the study could have opted to test for HIV outside the KPNC system and would not be reflected in our data. Before study completion, two PCPs withdrew from the intervention. Given the small study group, withdrawal from the study could have influenced the statistical significance on our results. Additionally, the centralised laboratory data system used to collect HIV testing data unique among many healthcare systems and report cards may be difficult to replicate in smaller, less integrated practice settings.

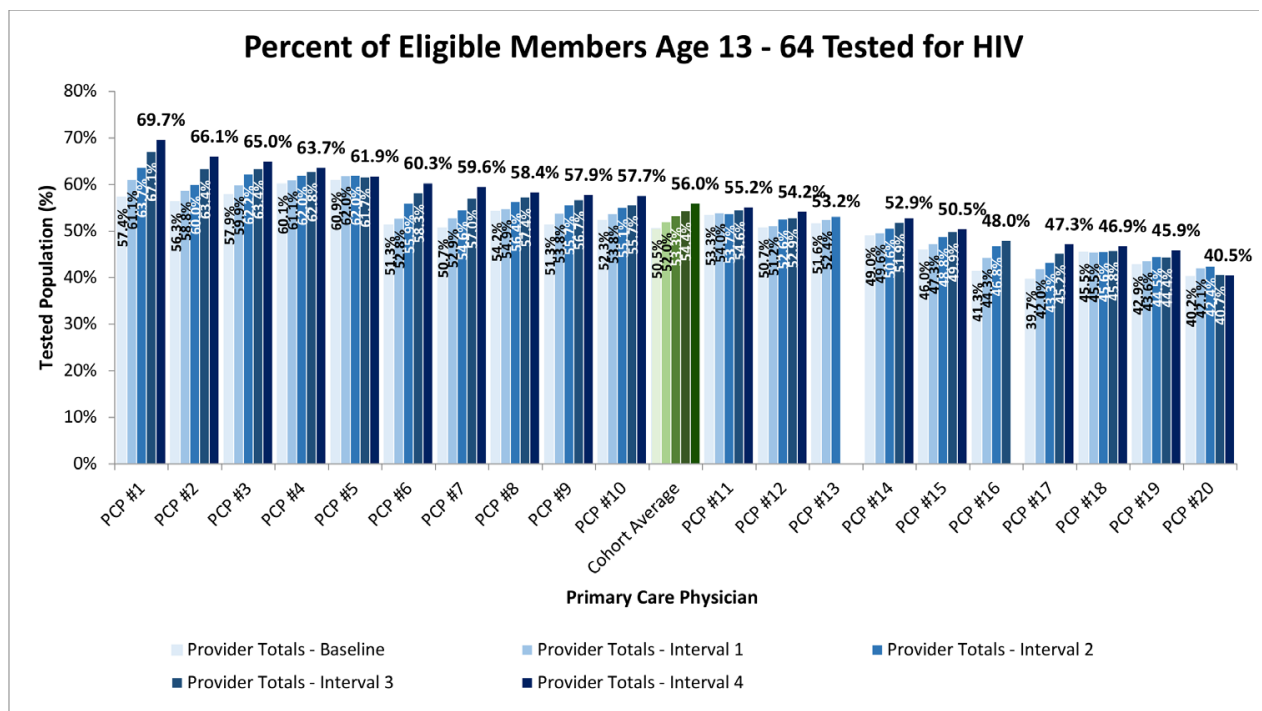

Figure 1 HIV screening report card for cohort primary care physicians. 
Table 3 Estimated increases in HIV screening over 12-month intervention

Change in \% screened over 12 months

Comparison of trend in \% screened over time by reference group

$\%$ screened at

$\mathbf{9 5 \%}$ confidence limit

$P$ value

\begin{tabular}{llllll}
\hline Cohort & $50.5 \%$ & $2.6 \%(1.9 \%, 3.2 \%)$ & $<0.0001$ & 0.022 & 0.073 \\
KPOAK & $38.1 \%$ & $1.9 \%(1.6 \%, 2.1 \%)$ & $<0.0001$ & $* *$ & Ref \\
KPNC & $29.2 \%$ & $1.8 \%(1.7 \%, 1.8 \%)$ & $<0.0001$ & Ref & $* *$ \\
\hline
\end{tabular}

${ }^{* *} \mathrm{P}$ value: 0.328 .

KPNC, Kaiser Permanente Northern California; KPOAK, Kaiser Permanente Oakland Medical Center.

Further steps can be taken to improve physiciantargeted HIV screening campaigns. With the support of system leadership and frequent quality improvement interventions, PCP awareness may improve and facilitate increases in HIV screening. Finally, inclusion of HIV ever screening in standardised PCP reminders through the electronic health record may further bolster testing rates. $^{28}$

\section{CONCLUSION}

Our results demonstrate that report cards can positively affect provider HIV screening practices in a large primary care group practice. With increased screening rates, our healthcare system can identify more people living with HIV and help prevent new infections and limit disease burden.

Acknowledgements We thank the primary care physicians at Kaiser Permanente Oakland Medical Center for their participation in this project. We also thank $\mathrm{Dr}$ Michael Silverberg of the Division of Research, Kaiser Permanente Northern California for providing analyst support for the project.

Contributors MNL, PYW, NR, HNT and SBS conceived and designed the project. MNL and PYW distributed the survey and collected survey data. MNL and SBS distributed the report cards. TL-H and LH collected HIV screening data and provided statistical analysis. MNL and PYW wrote and edited the manuscript. All authors approved the final manuscript.

Funding The authors have not declared a specific grant for this research from any funding agency in the public, commercial or not-for-profit sectors.

Competing interests None declared.

Patient and public involvement Patients and/or the public were not involved in the design, or conduct, or reporting, or dissemination plans of this research.

Patient consent for publication Not required.

Ethics approval The study was evaluated by the Research Determination Official at the Kaiser Foundation Research Institute (Reference number: RDO KPNC 19-089) and the study was not required to be reviewed by the Kaiser Permanente Institutional Review Board due to the nature of the study being quality improvement.

Provenance and peer review Not commissioned; externally peer reviewed.

Data availability statement Data are available upon reasonable request.

Open access This is an open access article distributed in accordance with the Creative Commons Attribution Non Commercial (CC BY-NC 4.0) license, which permits others to distribute, remix, adapt, build upon this work non-commercially, and license their derivative works on different terms, provided the original work is properly cited, appropriate credit is given, any changes made indicated, and the use is non-commercial. See: http://creativecommons.org/licenses/by-nc/4.0/.

ORCID ID

Mitchell N Luu http://orcid.org/0000-0002-9157-2025

\section{REFERENCES}

1 Centers for Disease Control and Prevention. Estimated HIV incidence and prevalence in the United States, 2010-2016. HIV surveillance supplemental report. 24, 2019.

2 Branson BM, Handsfield HH, Lampe MA, et al. Revised recommendations for HIV testing of adults, adolescents, and pregnant women in health-care settings. MMWR Recomm Rep 2006;55:1-4.

3 US Preventive Services Task Force, Owens DK, Davidson KW, et al. Screening for HIV infection: US preventive services Task force recommendation statement. JAMA 2019;321:2326-36.

4 Centers for Disease Control and Prevention. Hiv testing trends in the United States, 2000-2011. Atlanta, GA: U.S. Department of Health and Human Services, Centers for Disease Control and Prevention, 2013: 1-35.

5 Pitasi MA, Delaney KP, Oraka E, et al. Interval Since Last HIV Test for Men and Women with Recent Risk for HIV Infection - United States, 2006-2016. MMWR Morb Mortal Wkly Rep 2018;67:677-81.

6 Centers for Disease Control and Prevention (CDC). Previous HIV testing among adults and adolescents newly diagnosed with HIV infection - National HIV Surveillance System, 18 jurisdictions, United States, 2006-2009. MMWR Morb Mortal Wkly Rep 2012;61:441.

7 Dailey AF, Hoots BE, Hall HI, et al. Vital Signs: Human Immunodeficiency Virus Testing and Diagnosis Delays - United States. MMWR Morb Mortal Wkly Rep 2017;66:1300-6.

8 Dandachi D, Dang BN, Wilson Dib R, et al. Knowledge of HIV testing guidelines among US internal medicine residents: a decade after the centers for disease control and prevention's routine HIV testing recommendations. AIDS Patient Care STDS 2018;32:175-80.

9 Arbelaez C, Wright EA, Losina E, et al. Emergency provider attitudes and barriers to universal HIV testing in the emergency department. J Emerg Med 2012;42:7-14.

10 Rizza SA, MacGowan RJ, Purcell DW, et al. Hiv screening in the health care setting: status, barriers, and potential solutions. Mayo Clin Proc 2012;87:915-24.

11 Arya M, Phillips AL, Street RL, et al. Physician preferences for Physician-Targeted HIV testing campaigns. J Int Assoc Provid AIDS Care 2016;15:470-6.

12 Sokhi DS, Oxenham C, Coates R, et al. Four-Stage audit demonstrating increased uptake of HIV testing in acute neurology admissions using staged practical interventions. PLoS One 2015;10:e0134574.

13 Pillay TD, Mullineux J, Smith CJ, et al. Unlocking the potential: longitudinal audit finds multifaceted education for general practice increases HIV testing and diagnosis. Sex Transm Infect 2013;89:191-6.

14 Pillay K, Gardner M, Gould A, et al. Long term effect of primary health care training on HIV testing: a quasi-experimental evaluation of the sexual health in practice (SHIP) intervention. PLoS One 2018;13:e0199891.

15 Ivers N, Jamtvedt G, Flottorp S, et al. Audit and feedback: effects on professional practice and healthcare outcomes. Cochrane Database Syst Rev 2012;6:CD000259.

16 Burke RC, Sepkowitz KA, Bernstein KT, et al. Why don't physicians test for HIV? A review of the US literature. AIDS 2007;21:1617-24.

17 Arrington-Sanders R, Wheeler NJ, Matson P, et al. A system-level approach to improve HIV screening in an urban pediatric primary care setting. Pediatrics 2018;142. doi:10.1542/peds.2018-0506. [Epub ahead of print: 16 Oct 2018].

18 Davies CF, Kesten JM, Gompels M, et al. Evaluation of an educational intervention to increase HIV-testing in high HIV prevalence general practices: a pilot feasibility stepped-wedged randomised controlled trial. BMC Fam Pract 2018;19:195. 
19 Lubelchek RJ, Hotton AL, Taussig D, et al. Scaling up routine HIV testing at specialty clinics: assessing the effectiveness of an academic detailing approach. J Acquir Immune Defic Syndr 2013;64 Suppl 1:S14-19.

20 Brehaut JC, Colquhoun HL, Eva KW, et al. Practice feedback interventions: 15 suggestions for optimizing effectiveness. Ann Intern Med 2016;164:435-41.

21 Ivers NM, Sales A, Colquhoun $\mathrm{H}$, et al. No more 'business as usual' with audit and feedback interventions: towards an agenda for a reinvigorated intervention. Implement Sci 2014;9:14.

22 Yudin MH, Moravac C, Shah RR. Influence of an "opt-out" test strategy and patient factors on human immunodeficiency virus screening in pregnancy. Obstet Gynecol 2007;110:81-6.

23 Ross CE, Tao G, Patton M, et al. Screening for human immunodeficiency virus and other sexually transmitted diseases among U.S. women with prenatal care. Obstet Gynecol 2015;125:1211-6.
24 Lo CC, Runnels RC, Cheng TC. Racial/Ethnic differences in HIV testing: an application of the health services utilization model. SAGE Open Med 2018;6:2050312118783414.

25 Prosser AT, Tang T, Hall HI. Hiv in persons born outside the United States, 2007-2010. JAMA 2012;308:601-7.

26 Mimiaga MJ, Johnson CV, Reisner SL, et al. Barriers to routine HIV testing among Massachusetts community health center personnel. Public Health Rep 2011;126:643-52.

27 Elmahdi R, Gerver SM, Gomez Guillen G, et al. Low levels of HIV test coverage in clinical settings in the U.K.: a systematic review of adherence to 2008 guidelines. Sex Transm Infect 2014;90:119-24.

28 Kershaw C, Taylor JL, Horowitz G, et al. Use of an electronic medical record reminder improves HIV screening. BMC Health Serv Res 2018;18:14. 